continuing confusion that exists in the definition of recovery, remission, relapse and recurrence of depression, in spite of the pains that the authors took to use contemporary definitions and guideline recommendations for continuation and maintenance antidepressant treatment.

The definition adopted by the authors was derived from Frank et al (1991) where remission begins when a patient does not have any of the Research Diagnostic Criteria (RDC) symptoms of major depression. If remission is maintained for eight weeks, the patient is considered recovered. Return of symptoms of major/minor depression during the eight weeks after losing symptoms heralds a relapse, whereas if this occurs after an eight-week symptom-free interval the individual is considered to have had a recurrence. The pivotal importance given to a two-month symptom-free interval in differentiating a relapse from a recovery is embodied in DSM-IV (American Psychiatric Association, 1994) as well, whereas ICD-10 (World Health Organization, 1992) skirts the issue by using the phrase "several months" rather than commit itself to a definite time frame. However, continuation-phase treatment with antidepressants is usually recommended for four to six months after full recovery. Using the recommendation of four months of continuation treatment (Depression Guideline Panel, 1993), Ramana et al (1999) observed that 31 of 77 subjects who 'recovered' from depression had a return of symptoms in the continuation phase of antidepressant treatment. This implies that they had not actually recovered from the underlying pathophysiology of the episode but had only achieved symptomatic recovery. They would be then classified as having had a relapse rather than a recurrence, as would be the case if Frank et als definition (1991) were followed.

A recent randomised controlled trial by Reimherr et al (1998) on the optimal length of continuation therapy in depression addresses this crucial issue in the research and treatment of depressive disorders. Based on their trial, which involved prospective transfer to placebo at multiple points, the authors recommend an additional 26 weeks of fluoxetine after remission to prevent re-emergence of depressive symptoms, thereby proposing that the end of this period defines recovery from the underlying pathophysiology of an episode of depression. This suggests that two months of remission, as proposed by Frank et al (1991) and in DSM-IV, is inadequate to define complete recovery from an episode of depression, and warrants fresh attempts to achieve consensus definitions for remission, recovery, relapse and recurrence in major depressive disorder.

American Pyychiatric Association (1994) Diagnostic and Statistical Monual of Mental Disorders (4th edn) (DSM-IV). Washington, DC: APA.

Depression Guideline Panel (1993) Clinical Proctice Guideline. Number 5, Depression in Primory Core; Volume 2. Treatment of Major Depression. Rockville, MD: Agency for Health Care Policy and Research.

Frank, E., Prien, R. F., Jarrett, R. B., et al (1991) Conceptualisation and rationale for consensus definitions of terms in major depressive disorder: remission, recovery, relapse, and recurrence. Archives of General Psychiotry, 48, 85I-855.

Ramana, R., Paykel, E. S., Surtees, P. G., et al (1999) Medication received by patients with depression following the acute episode: adequacy and relation to outcome. British joumal of Psychioury, 174. 128-134.

Reimherr, F. W., Amsterdam, J. D., Quittin, F. M., et al (1996) Optimal length of continuation therapy in depression: a prospective assessment during long term fluoxetine treatment. American journol of Psychioury, 155 1247-1253.

World Heatth Organization (1992) Internotional Classificotion of Diseoses (ICD-10). Geneva: WHO.

P.Tharyan, G. Raghuthaman Department

of Psychiatry, Christian Medical College.

Vellore-632002, Tamil Nadu, India

\section{Criteria for traumatic grief and PTSD}

Sir: We were interested in Prigerson et al's (1999) consensus criteria for traumatic grief. There were some concepts in the distinction from post-traumatic stress disorder (PTSD) with which we would take issue. Criterion B, in particular, appears to overlap significantly with PTSD. Avoidance of reminders is one of the key criteria in DSM-IV PTSD (American Psychiatric Association, 1994), as well as emotional numbing. In fact, most of Prigerson et al's criterion B can be seen in PTSD. We also feel concerned about the two months of symptoms which the authors have used as a time scale, since clinically this overlaps with normal grief. The distinctness of this diagnosis must, therefore, be questioned. No mention is made of the adjustment reaction and the distinction from this, and in ICD-10 (World Health Organization, 1992) many atypical grief reactions are put in this section.

The authors had a $42 \%$ response rate in their study which was predominantly female, of a mean age of 61 years and Caucasian. This undermines the generalisability of the study. Furthermore, in our clinical work on PTSD, avoidance symptoms often delay presentation and this might be significant in the rest of their sample.

Post-traumatic stress disorder is a condition with a $50-95 \%$ comorbidity (Green $e t$ $a l, 1992)$ and it is inherently problematic to sort out comorbidity (Yehuda \& Mcfarlane, 1995). Further, a recent epidemiological study found a risk of developing PTSD of $31 \%$ following unexpected death of a loved one (Breslau et al, 1998). A recent paper reinforced the link between grief and PTSD, showing that they appear to share common predictors (Sprang \& $\mathrm{McNeil}$, 1998). If this is the case, then perhaps PTSD and traumatic grief syndrome represent a spectrum of severity, or are potential alternatives, or are potentially comorbid. We also wonder whether including this as a sub-specifier in PTSD might be a better place for it, rather than as a distinct diagnosis. The work which the authors have undertaken is preliminary but we feel may assist in the better definition of PTSD and traumatic grief.

American Poychiatric Assoclation (19\%4) Diognostic and Statistical Manual of Mentol Disorders (4th edn) (DSM-N). Washington, DC: APA.

Breslau, N., Kessler, R. C., Chilcont, H. D., ot ol (I990) Trauma and PTSD in the community: the 1996 Detroit area survey of trauma. Americon fournol of Psychiotry, 155, 626-632.

Green, B. L., Uindy, J. D., Grace, M. C., et al (1992) Chronic PTSD and diagnostic comorbidity in a disaster sample. foumal of Nervous and Mental Disease, 180. 760-766

Prigerson, H. G., Shear, M. K., Jacobe, S. C., ot al (1999) Consensus criteria for traumatic grief. A preliminary empirical test. British journal of Psychiatry, $174,67-73$

Sprang, G. \& McNell, 1. (1998) Post-homicide reactions: Grief, mourning and post-traumatic stress disorder following a drunk driving fatality. fournol of Deoth and Dying, 37, 4!-58.

Yehuda, R. \& Mefartane, A. C. (1995) Conflict between current knowledge about PTSD and its original conceptual basis. Americon journol of Psychiotry, 152. $1705-1713$.

World Health Organization (1992) International Classification of Diseases (KDD-10). Geneva; WHO

G. C. Fox, G. E. Reid, A. Salmon, P. Mckillop-Duffy, C. Doyle Department of Community Psychiatry, RAF Brize Norton, Oxford OXI8 $3 L X$

Authors' reply: We appreciate the attention Dr Fox and colleagues have drawn to the distinction between the criteria for PTSD and those we propose for traumatic grief. As stated in our article: "we acknowledge the reaction to be a stress response syndrome 